\title{
O projeto político-pedagógico dos movimentos sociais: o que a educação formal tem para aprender com eles?
}

\begin{abstract}
Ane Carine Meurer*
Cesar De David**

\section{Resumo}

O presente artigo pretende discutir as rupturas existentes entre a escola formal e a pedagogia dos movimentos sociais, enfocando, de forma particular, o Movimento dos Trabalhadores Rurais Sem Terra (MST). Queremos chamar a atenção para a possibilidade das escolas formais, em seus projetos político pedagógicos, reconhecerem as possibilidades de troca de saberes que os movimentos sociais oferecem. Tentamos, pois, resgatar algumas abordagens que definem 0 que são os movimentos sociais e as suas práticas pedagógicas, tendo como referência o Movimento dos Trabalhadores Rurais Sem Terra (MST), a fim de que o conhecimento amealhado pelo movimento possa ser aprendido pela escola formal, enriquecendo sua leitura e escrita de mundo.
\end{abstract}

Palavras-chave: projeto político-pedagógico; escola; movimentos sociais; educação do MST.

\section{The political-pedagogical project of social movements: what formal education has to learn from them?}

\begin{abstract}
The following articule discusses the ruptures between formal school and the pedagogy of social movements such as the MST (Movement of Landless Workers). It intends to draw attention to the possibility of formal schools to recognize in their political projects the possibilities of change that is offered by social movements. It also tries to rescue some approaches that would define what exactly means the social movements and their teaching practices, with reference to the Movement of Landless Workers (MST). It is supposed that this knowledge can be learned through formal schooling, enriching their reading and writing the world.
\end{abstract}

Keywords: political and pedagogical projects; school; social movements; MST education.

\footnotetext{
* Professora Doutora da Universidade Federal de Santa Maria (UFSM), Centro de Educação, Santa Maria, Rio Grande do Sul, Brasil.

** Professor Doutor da Universidade Federal de Santa Maria (UFSM), Centro de Ciências Naturais e Exatas. Santa Maria, Rio Grande do Sul, Brasil.
} 


\title{
Ane Carine Meurer - Cesar De David
}

\section{Introdução}

A experiência histórica e cultural dos educandos, educadores e de toda a comunidade, geralmente, é desconsiderada pela escola formal, que se torna espaço-tempo de transmissão dos conhecimentos acumulados pela humanidade nas várias áreas do conhecimento. Embora a escola formal tenha ampliado suas condições de acesso às classes populares, em grande parte, a sua permanência pode ser questionada, principalmente quando se trata de uma escola que atende crianças, jovens e adultos advindos de um movimento social.

\begin{abstract}
Hoje, praticamente, não há país no mundo que não garanta, em seus textos legais, o acesso de seus cidadãos à educação básica. Afinal, a educação escolar é uma dimensão fundante da cidadania, e tal princípio é indispensável para políticas que visam à participação de todos nos espaços sociais e políticos e, mesmo, para reinserção no mundo profissional. (CURY, 2002, p. 246)
\end{abstract}

A institucionalização da escola desempenha várias funções sociais, entre elas, a formação de trabalhadores para desempenhar tarefas no mundo do trabalho, a transmissão da ideologia para a manutenção da estrutura social e dos conhecimentos historicamente acumulados. No entanto, não podemos negar que sem a escola as gerações que vivem do trabalho teriam ainda maiores dificuldades de se inserirem no mundo do trabalho.

Nesse sentido, a escola é uma instituição paradoxal porque, de um lado, perpetua as práticas pedagógicas e sociais, enquanto, por outro lado, permite a sua reconstrução. Queremos argumentar que os movimentos sociais são importantes para que o processo de abertura e troca efetive-se, pois possibilitará a realização de novas leituras de mundo por parte de educadores e educandos. Ambos terão que aprender uns com os outros, com as suas experiências e poderão transformar a escola em espaço-tempo em que ditas experiências sejam compartilhadas, as quais poderão ser ponto de partida para a leitura e a escrita de mundo e, se articuladas com os saberes científicos, poderão ser compreendidas e servir de instrumento de emancipação desses sujeitos.

A escola é uma construção institucionalizada, mantida e transformada pelas práticas pedagógicas e sociais. Nesse espaço, há uma ampla rede de significados que dá sentido e forma às situações e às circunstâncias da sociedade e do mundo.

Todas as escolas têm um projeto pedagógico, o que as diferencia é o fato de que elas nem sempre têm refletido coletivamente com pais, alunos, professores, funcionários e comunidade. Dificilmente se explicita: a quem a escola serve? O que se quer atingir por meio dela? Quais são os valores presen- 
O projeto político-pedagógico dos movimentos sociais:

o que a educação formal tem para aprender com eles?

tes na comunidade escolar? entre outras questões. O que comumente tem ocorrido é que as escolas executam o projeto proposto, sem que se estabeleçam relações entre os sujeitos que dela fazem parte. Disso resulta uma série de fragmentações que, na maioria das vezes, dificulta a dinamicidade na reconstrução de seu projeto.

Expressar, discutir, argumentar sobre que sujeito se tem a intenção de formar, para qual sociedade e quais as condições oportunizadas para que isso ocorra são atividades pouco frequentes nas escolas brasileiras e, por esta razão não há diálogo entre os sujeitos sociais que as constituem, nem mesmo entre os educadores, o que inviabiliza um projeto comum, que aponte para a formação da consciência crítica de educandos e educadores.

O que se quer dizer com isso é que tal projeto não pode ser assumido por uma ou outra disciplina. Assim sendo, a escola, em seu conjunto, toma tal missão para si ou continuam as desarticulações, as fragmentações e as rupturas de suas práticas e intenções. Um exemplo que a escola pode seguir com vistas à superação dessas questões pode vir da leitura dos movimentos sociais e de suas práticas. A escola formal pode aprender com eles? Esta é a questão que o presente texto pretende discutir.

\section{Os movimentos sociais e seus projetos}

As pesquisas, no Brasil, a respeito dos movimentos sociais têm avançado muito nos últimos tempos, mas é certo que não temos condições, ainda, de pensar em um referencial teórico que dê conta de abarcar a totalidade das práticas implementadas por esses movimentos. Nesse sentido, estudar os referidos movimentos é sempre instigante e desafiador para os pesquisadores que devem tentar compreendê-los, considerando as suas singularidades e diferenças. Gohn (2004, p. 327) afirma que

[...] não há uma teoria única, assim como não há uma só concepção para o que seja um movimento social, e não há também um só tipo de movimento social. Há várias teorias formuladas em paradigmas teóricos explicativos.

Encontramos muita dificuldade em explicitar teoricamente os movimentos sociais em função de que eles são ações coletivas que surgem em decorrência de várias problemáticas sociais, de múltiplos olhares, de diferentes comportamentos e dos mais variados contextos culturais. Além disso, organizam-se em decorrência de demandas desencadeadas pelos sujeitos envolvidos quando eles se reconhecem como detentores de um direito a ser reivindicado. Ainda segundo Gohn (2004, p 19-20),

Os movimentos sociais são fenômenos históricos decorrentes de lutas sociais. Colocam atores específicos sob as luzes da ribalta em períodos determinados. Com 


\begin{abstract}
as mudanças estruturais e conjunturais da sociedade civil e política, eles se transformam. Como numa galáxia espacial, são estrelas que se acendem enquanto outras estão se apagando, depois de brilhar por muito tempo. São objetos de estudo permanente. Enquanto a humanidade não resolver seus problemas básicos de desigualdades sociais, opressão e exclusão, haverá lutas, haverá movimentos. E deverá haver teorias para explicá-los: esta é a nossa principal tarefa e responsabilidade, como intelectuais e cidadãos engajados na luta por transformações sociais em direção a uma sociedade mais justa e livre.
\end{abstract}

É importante destacarmos que os movimentos sociais foram e são muito significativos para a sociedade. Assim o são desde que ela se proponha a compreender o momento histórico no qual se encontra, assim como os limites e as possibilidades que lhe são próprios, almejando-se, neste caso, a reconstrução de uma sociedade mais justa, igualitária e livre. Sendo assim, as decisões político-pedagógicas tomadas tanto em nível econômico quanto social, cultural, político são decorrentes de tensionamentos promovidos pelos vários segmentos da sociedade e, também, pelos movimentos sociais.

Os movimentos também podem ser considerados espaços-tempos de esperança e de reconstrução da ordem socialmente estabelecida, isto é, espaços-tempo de expressão das pluralidades.

Para Scherer-Warren (2008), os movimentos sociais podem ser meIhor compreendidos a partir da ideia de "ação coletiva". Esse termo "tem sido geralmente utilizado como um conceito empírico para se referir às formas de associações civis, agrupamentos para a defesa de interesses civis ou público..." (SCHERER-WARREN, 2008, p. 440). Ele faz referência a diferentes níveis de atuação: localizado e restrito, como uma organização não governamental (ONG), ou em esfera universal, como um movimento social propriamente dito. $\mathrm{E}$ ainda, analisando a obra de Melucci, Scherer-Warren afirma que:

A noção de ação coletiva não se refere, nessa teorização, a ações não estruturadas, que não obedecem alguma lógica de racionalidade, como os tumultos públicos espontâneos, por exemplo. Ela envolve uma estrutura articulada de relações sociais, circuitos de interação e influência, escolhas entre formas alternativas de comportamento [...]. Os movimentos sociais seriam uma das possibilidades dessas ações. Dessa forma: enquanto categoria analítica, o movimento social designa a forma de ação coletiva que envolve solidariedade, manifesta um conflito, excede os limites de compatibilidade do sistema em relação à ação em pauta. (SCHERER-WARREN, 2008, p. 441) 
O projeto político-pedagógico dos movimentos sociais:

o que a educação formal tem para aprender com eles? sociais como:

Assim, Scherer-Warren (2008, p. 442) também define os movimentos

[...] redes sociais complexas, que transcendem organizações empiricamente delimitadas e que conectam de forma simbólica, solidarística e estratégica, sujeitos individuais e atores coletivos, em torno de uma identidade ou identificações comuns, definição de um campo de conflito e de seus principais adversários políticos ou sistêmicos e de um projeto ou utopia de transformação social. As identidades e os conteúdos das lutas podem ser específicos (ambientalista, feminista, étnico etc.) ou transidentitários (eco-feminismo, antirracismo ambientalista, educação popular, educação indígena etc.).

Portanto, o projeto político-pedagógico de um movimento social visa concretizar uma profunda reflexão crítica sobre si (o movimento), as relações que estabelece com os seus participantes e com os outros movimentos. Além disso, procura realizar uma ampla discussão sobre a conjuntura política, econômica, social na qual se acha inserido e como a educação poderá contribuir para a compreensão dessas relações e a efetivação de mudanças através das suas ações. Por meio da investigação dessas relações e de um olhar peculiar, revestido de valores e ideologia (politicamente demarcado), definem um lugar de produção de conhecimento, passível de ser compreendido pela academia, mas que os singulariza na sua experiência e que poderá ser instigador de outras experiências, inclusive para a educação formal.

Nesse contexto, ficaram claras as diversas posturas, os valores, as diversidades que compõem determinado grupo social e, nesse debate articulado com uma vivência, se estabelecem outras relações e reconstroem-se conhecimento sob outras bases.

O projeto político-pedagógico aponta um rumo, uma direção, um sentido explícito para um compromisso estabelecido coletivamente. O projeto pedagógico, ao se constituir em processo participativo de decisões, preocupa-se em instaurar uma forma de organização do trabalho pedagógico que desvele os conflitos e as contradições [...] (VEIGA, 1998, p. 13)

Nesse sentido, a escola, ao abrir-se para os movimentos sociais, poderá aprender sobre as suas formas de ler e escrever o mundo. Estaríamos nos comprometendo com uma educação de qualidade, considerando as múltiplas necessidades sociais e culturais de uma população. Essa perspectiva constituiria a efetivação da articulação da escola com os direitos humanos. 


\section{Ane Carine Meurer - Cesar De David}

\section{Olhares compreensivos para o estudo dos movimentos sociais}

Segundo Gohn (2004, p. 44): "[...] Distinto das organizações institucionalizadas, marcadas pela estabilidade, o movimento social é, por definição, dinâmico [...]". A dinamicidade é uma característica que está diretamente ligada aos movimentos sociais e quando essa perspectiva é perdida ou deixada de lado pode-se afirmar que ele se organiza de forma diferente e não mais como movimento.

Fazendo uma retrospectiva histórica dos movimentos sociais, Gohn (2004) interpreta que, em alguns momentos, os teóricos reconheciam os movimentos sociais como um perigo para a democracia; no entanto, a autora conclui que eles constituem a vitalidade da sociedade democrática.

De acordo com a mesma autora, ao fazer uma análise das teorias norte americanas, compreendemos que, para analisarmos os movimentos sociais, seria necessário entender os valores, as normas, as ideologias, os projetos, a cultura e identidade dos grupos sociais estudados. Ainda seria imprescindível analisar as relações sociopolíticas que estão implicadas na realidade local e global.

Entre os autores norte-americanos citados pela autora, selecionamos alguns que, de algum modo, nos ajudam a compreender a realidade por nós trazida, entre eles [...] "para Oberschall, movimento social significa, prioritariamente, organização" (GOHN, 2004, p. 63).

Com auxílio dos autores abordados por Gohn, percebemos que, para que possamos construir um entendimento acerca de um movimento social, teríamos que procurar analisar a classe social das pessoas, que inclui a sua identidade coletiva, o processo de formação da consciência dos seus integrantes e como a solidariedade manifesta-se entre elas. É importante também observarmos e compreendermos como o movimento surge, como se mobiliza e porque emerge em determinado espaço-tempo; dessa forma, seria possível analisarmos as bases sociopolíticas dos movimentos. Além disso, é imprescindível entendermos a forma que promovem o recrutamento e a mobilização do movimento (GOHN, 2004)

Ainda com auxílio dessa autora, destacamos que é fundamental compreendermos o papel das comunicações dentro dos movimentos sociais. Devemos analisar o movimento social como um processo e não como fenômenos isolados, assim como as questões simbólicas presentes nos movimentos sociais e na sociedade. É relevante entender a relação do movimento com o estado e com a conjuntura política a fim de possibilitar sua formação e organização. A leitura da conjuntura política social, local e mundial precisa detectar as oportunidades políticas (GOHN, 2004). 
O projeto político-pedagógico dos movimentos sociais:

o que a educação formal tem para aprender com eles?

Nesse aspecto, interessar-se pelo momento histórico em que o movimento social surge e as relações que essa ação coletiva teve e tem com o contexto político, social, cultural, presente e passado, fará com que haja uma melhor compreensão de seus objetivos, seus motivos e suas práticas, entre outros aspectos.

O movimento social, ao organizar os sujeitos envolvidos, reconstrói as identidades individuais em coletivas; portanto, tem um potencial transformador que precisa ser abordado para que possamos analisar as novas identidades que se constituem.

Outro aspecto importante seria entendermos que "[...] Os movimentos sociais são analisados em termos de estruturas de poder ou como produtores de poder". (GOHN, 2004, p. 112) Suas representações, que também estão dentro das instituições, envolvem a questão do poder.

Esses aspectos analisados para a compreensão do que é um movimento social poderão integrar o projeto da escola, para que esta amplie a sua própria escrita e leitura de mundo.

\section{A escola aprendendo com os movimentos sociais: o exemplo do MST}

Precisamos, como educadores, entender o espaço-tempo no qual estamos inseridos. Como podemos chegar à compreensão do mundo se há muitas barreiras entre nós (filtros) que impedem nosso "contato" com ele? O mundo é conhecido a partir da tematização do mundo vivido. Essa compreensão é reconstruída a partir das construções prévias, do conhecimento que já possuímos. A tematização do mundo da vida refere-se a um saber que dominamos porque pertencemos a uma determinada cultura.

Uma primeira barreira que o educador precisa romper é o desconhecimento que tem dos seus educandos, da realidade em que vivem e das relações que suas famílias estabelecem com o mundo. Educadores e educandos possuem visões de mundo, valores e aspirações diferentes e, na maioria das vezes, antagônicas e conflitantes. Fazer com que esse dado possa emergir na sala de aula e possibilitar a convivência com as diferenças pode ser um primeiro passo para a aprendizagem desse mundo. Em grande medida, na pedagogia dos movimentos sociais, esse confronto, geralmente, não está estabelecido, pois educadores e educandos compartilham vivências e aspirações que estão na base do movimento do qual fazem parte.

Esta produção de conhecimento [...] é evidentemente orientada por considerações de caráter mais pragmático do que acadêmico. O conhecimento produzido pelas malhas deveria ser uma parte importante das próprias atividades de teorização e das agendas de investigação dos universitários. Já não estamos na situação em que 
alguns produzem conhecimento (universitários, intelectuais) para outros aplicarem (movimentos sociais). Actualmente, essas fronteiras estão completamente em ruptura à medida que os movimentos se transformam em produtores de conhecimento e os intelectuais são chamados a envolverem-se cada vez mais no activismo. (ESCOBAR, 2006, p. 652-653)

Em pesquisas atuais em município do interior do estado do Rio Grande do Sul, onde há muitos assentamentos recentemente implantados, ligados ao MST, percebemos que as escolas formais, nas quais estudam as crianças assentadas, estão fechadas para as experiências, concepções e modo de vida dos infantes. No cotidiano escolar, no currículo e no projeto pedagógico, essas crianças estão ausentes pelo fato de integrarem um movimento fortemente combatido pela elite agrária local que, coincidentemente, controla as estruturas do poder municipal. As crianças, nesse caso, estão submetidas a uma situação que contraria todo o projeto pedagógico do movimento, cujos pilares assentamse na autonomia de gestão e organização escolar e na forte vinculação dos conhecimentos à realidade do mundo e do trabalho.

Foi a ação social coletiva do MST que possibilitou a conquista de políticas públicas, construídas a partir de um processo educativo. Os acampados e assentados transformaram-se em sujeitos solidários e ativos, capazes de criticar a realidade, mas também, por meio da sua ação, lutar e efetivar a transformação social.

Para Souza:

[...] os movimentos sociais populares têm constituído uma espaço permanente de confronto de saberes num processo em que as necessidades populares se transformam em demandas sociais (econômicas e ideológicas) e se elaboram propostas para sua satisfação: projetos emergenciais e históricos. (SOUZA, 2007, p. 49)

Para o movimento, a escola não é, nem deve ser, um espaço-tempo que apenas prepara os indivíduos para o exercício futuro da cidadania. A escola pode e deve ser um espaço que permite a todos os sujeitos da educação o exercício pleno da cidadania, oportunizando a participação coletiva, a reflexão e a discussão de diferentes pontos de vista.

Para o MST, pensar a educação escolar é trabalhar na perspectiva de superar a tecnicização pela qual a escola e a universidade têm se pautado e construir um ensino articulado ao mundo da vida e do trabalho, lutando, como consequência, para a sua efetivação. 
O projeto político-pedagógico dos movimentos sociais:

o que a educação formal tem para aprender com eles?

O educador deve pautar a sua práxis no reconhecimento do direito à educação de qualidade para todos, na valorização e no respeito às diversas culturas, modos de vida e diferentes saberes a fim de compreender que todos têm direito aos bens sociais, econômicos, culturais oferecidos pela educação. Educação que, nesse caso, é compreendida como uma das possibilidades de transformação social e, portanto, que ela seja reconhecida em sua dimensão ético-política, direito inalienável que se faz presente nas sociedades modernas.

\section{Reflexões sobre a prática: o MST e sua pedagogia}

A escola formal, entendida como reprodutora de um sistema capitalista, não atende as necessidades dos movimentos sociais. Nesse contexto, observa-se um paradoxo: se de um lado, a maneira como estão sendo trabalhados os conhecimentos formais nas escolas gera alienação (aceitação), desarticulação do que temos com o que queremos, de outro lado, não podemos prescindir deles e, assim, os conhecimentos historicamente acumulados, os conceitos presentes nos currículos oficiais são indispensáveis para que possamos realizar nossos projetos de vida, de educação e de sociedade.

Por seu turno, a pedagogia do MST traz, para o contexto social, a luta por uma sociedade alternativa e que pode ser construída através da educação. A construção de uma escola que possa vir a ser uma escola dos sujeitos Sem Terra passa pela disputa político-pedagógica entre as concepções de educação do estado e do MST. E, do mesmo modo, o debate acerca da educação que temos, hoje, perpassa a contextualização do país e, portanto, das crises econômicas, da influência de agentes externos e da própria política neoliberal. A luta contra esse conjunto de políticas vem através de um projeto alternativo que garanta o acesso ao conhecimento pelas camadas populares.

Se a questão educacional brasileira precisa ser transformada, o que dizer da educação do campo? Este setor, em específico, apresenta sérios problemas, a começar pela falta de investimentos que denota pouca atenção para uma realidade diferenciada. O campo é visto como o lugar do atraso, deficiente e, em geral, os currículos das escolas não estão interligados com a sua realidade, distanciando-se ainda mais da sua própria identidade, da sua cultura. A falta de tempo disponível para interação dos educadores com a realidade escolar também contribui para aumentar a lacuna entre teoria e prática. Faz-se necessário construir uma educação voltada para o campo que assuma a sua identidade e cultura. Isso implica mudança de conceitos, conteúdos, valores, habilidades e atitudes por parte do educador e dos educandos, de modo que tal proposta exige espaço-tempo de reflexão conjunta, coletiva e solidária, aspecto que não ocorre de uma hora para a outra, mas exige intencionalidade, desprendimento, responsabilidade, organização, entre outros aspectos.

Geralmente, os educadores oriundos de escolas urbanas não estão habituados ao cotidiano rural e, por sua vez, não têm tempo disponível para 


\section{Ane Carine Meurer - Cesar De David}

integrar-se à comunidade escolar, conhecendo-a um pouco mais, para assim, contribuir no processo de construção de um currículo diferenciado. Esses e outros problemas fizeram com que o MST lutasse pela concretização da educação nos assentamentos e acampamentos.

A escola do MST configura-se como um projeto educacional diferenciado das instituições de ensino formais e, portanto, não pode ser refletida tão somente a partir de conceitos e caracterizações oriundas do espaço educativo formal. Nas escolas formais, a finalidade do ato educativo ainda centra-se na apropriação do conhecimento sistematizado, enquanto isso, nas escolas do MST, o fim da educação é a humanização do sujeito Sem Terra, mediatizada pelo saber historicamente sistematizado, ou seja, a apropriação e a construção do conhecimento devem vislumbrar a formação humana de educadores e educandos.

Nas escolas do MST, o currículo é ressignificado ao referendar um novo projeto educacional, que compreende dimensões e práticas de formação humana. Trabalha-se com a concepção de ambiente educativo, o qual diz respeito a ações pedagógicas intencionais que perpassam o ambiente escolar: 0 que se faz, produz, diz, vive e participa.

Quando Caldart (2001) trata da pedagogia do movimento, evidencia nitidamente a concepção freiriana de que a educabilidade do ser humano assenta-se na sua inconclusão, no seu não condicionamento e, por conseguinte, na possibilidade que ele tem de ser mais do que é. O autor compreende a natureza humana num processo dinâmico, constituindo-se social e historicamente.

Segundo Caldart (2001), aprender a ser Sem Terra acontece no ato de conviver, participar e assumir essa identidade: as ações produzem e não são produzidas por meio de relações sociais. Essa construção é fortalecida nas relações e ações de luta, que se referem às ocupações de terra, mobilizações, místicas e às organizações coletivas que se formam em acampamentos e assentamentos. São espaços-tempos educativos que ultrapassam e complementam o âmbito escolar.

Entre as dimensões que compreendem o ambiente educativo, Caldart (2001) expõe: a formação de valores e a educação da sensibilidade; o cultivo da memória e o aprendizado da história; a produção de conhecimentos humanamente significativos; a formação para o trabalho; a formação organizativa; a formação econômica e a formação política. No que se refere às práticas educativas, a autora destaca: aulas, oficinas, trabalho e produção, gestão coletiva, atividades artísticas e lúdicas, participação em ações do movimento fora da escola e sistematização das práticas.

Dessa forma, nas escolas do MST, a função primeira da educação é a humanização do sujeito Sem Terra, aliada à reflexão crítica da realidade especí- 
O projeto político-pedagógico dos movimentos sociais:

o que a educação formal tem para aprender com eles?

fica em que vive e do modelo social vigente, indo ao encontro do que Freire (1992, p. 12) entende ser o pressuposto fundante da ação educativa: "humanizar o homem na ação consciente que este deve fazer para transformar o mundo".

Por meio de seu projeto político-pedagógico, a escola do MST tem se mostrado uma possibilidade para a educação popular, uma vez que vem contribuindo para a formação do ser no mundo, efetivando o acesso a um direito básico. Isso ocorre através do diálogo dos saberes do mundo vivido (leitura de mundo proposta por Freire) e o conhecimento sistematizado. Esse diálogo exige comprometimento, que se viabiliza através do reconhecimento da realidade do outro, das suas necessidades, comprometendo-se com a sua emancipação e da coletividade.

Às escolas formais, a partir da experiência da educação desenvolvida pelos movimentos sociais, de forma particular pelas escolas do MST, impõe-se a necessária reconstrução de seus projetos político-pedagógicos a fim de que seus currículos tenham em vista o direito à escola socialmente significativa, que venham ao encontro da discussão crítica sobre as questões políticas, econômicas e sociais que dizem respeito aos sujeitos sociais que fazem parte dela.

\section{Considerações finais}

Entendemos que a escola formal é espaço-tempo de formação que necessita ser ocupado pelos sujeitos históricos e políticos que fazem parte dela: educadores, educandos, funcionários, pais e comunidade em geral. Pretendemos, com isso, assumir a função de compreender as problemáticas relacionadas à terra e à escola que, com seu projeto político-pedagógico, poderá vir ao encontro desses interesses.

As experiências pedagógicas dos movimentos sociais são plasmadas pela criticidade e pela aprendizagem por todos os envolvidos. Essas experiências podem servir para as escolas formais reconstruírem seus projetos político-pedagógicos superando a educação alijada da realidade das classes trabaIhadoras, por meio de projetos que não problematizam, compreendem e transformam a realidade social.

Assim sendo, muito ainda temos que trabalhar no sentido de transformar a instituição escolar em espaço-tempo no qual se articula a educação popular, independente do nível de ensino. Desse modo, optamos trabalhar na perspectiva de que, formando trabalhadores em educação comprometidos com essas realidades, com esses projetos político-pedagógicos já faremos algo, superando, assim, a educação que vem sendo desenvolvida nos vários espaçostempos formais e não-formais. Com tais compromissos, acreditamos que o direito à educação terá mais possibilidade de efetivar-se. 
Perspectivas relacionadas à discussão do currículo e ao projeto político-pedagógico localizam-se no âmbito da criticidade, da responsabilidade, vinculadas à compreensão de que não somos excluídos do direito à educação simplesmente, mas há um projeto social, histórico que nos mantém nessa posição, nesse lugar. Admiti-lo é um passo para a organização de outras ações, função de todos os que se aventuram a discutir, refletir e construir outro projeto político-pedagógico social, a exemplo do que vêm fazendo os movimentos sociais do campo.

Os movimentos sociais possibilitam a incerteza, confrontam-nos com as rupturas, pois as transformações que engendram superam o estabelecido, apontam outros caminhos, tencionam as relações, tendo em vista um projeto de vida coletivo. Almejamos, nesse sentido, que a escola formal possa ter, também, um projeto pedagógico seu, escutando os movimentos que a integram, enriquecendo a sua leitura e escrita de mundo.

\section{Referências}

CALDART, R. S. O currículo das escolas do MST. Alfabetização e cidadania. São Paulo: Rede de Apoio à Ação Alfabetizadora no Brasil. Revista N.11, Abril de 2001.

CURY, C. R. J. Direito à educação: direito à igualdade, direito à diferença. Cad. Pesqui. [online]. 2002, n.116, p. 245-262. Acesso em: 14 fev. 2012.

DAL RI, N. M.; VIEITEZ, C. G. A educação do Movimento dos Sem-Terra: Instituto de Educação Josué de Castro. Educ. Soc. [online]. 2004, vol. 25, n. 89, p. 1379-1402. ISSN 0101-7330. acesso em: 14 fev. 2012.

ESCOBAR, A. Actores, redes e novos produtores de conhecimento: os movimentos sociais e a transição paradigmática nas ciências. In: SANTOS, B. de S. (Org.). Conhecimento prudente para uma vida decente. São Paulo: Cortez, 2006. p. 639-666.

FREIRE, P. Pedagogia do oprimido. Porto Alegre: Mercado Aberto, 1992.

GOHN, M. da G. Teoria dos movimentos sociais: paradigmas clássicos e contemporâneos. São Paulo: Loyola, 2004.

SCHERER-WARREN, I. Ações coletivas e movimentos sociais: revisitando conceitos. In: QUARTIERO, E. M.; SOMMER, L. H. (Orgs.). Pesquisa, educação e inserção social: olhares da Região Sul. Canoas: ULBRA, 2008. p. 439-448.

SOUZA, J. F. Educação popular e movimentos sociais no Brasil. In: CANÁRIO, R. (Org.). Educação popular \& movimentos sociais. Lisboa: Educa, 2007. p. 37-80.

VEIGA, I. P. A. Perspectivas para a reflexão em torno do projeto político-pedagógico. In: VEIGA, I. P. A.; RESENDE, L. M. G. (Org.). Escola: espaço do projeto político-pedagógico. Campinas: Papirus, 1998. p. 09-32. 
O projeto político-pedagógico dos movimentos sociais: o que a educação formal tem para aprender com eles?

\section{Correspondência}

Ane Carine Meurer - Av. Roraima, 1000 - Universidade Federal de Santa Maria/Centro de Educação, CEP: 97105-900 - Santa Maria, Rio Grande do Sul.

E-mail: acmeurer@terra.com.br

Recebido em 15 de janeiro de 2012

Aprovado em 21 de maio de 2012 